\section{Traversing the American Dream in Medical School - The FGLI Experience}

JENNIFER A. FOKAS, BA (D)

BRIDGER M. RODONI, BS

LAUREN C. LAMONICA, BS, MPH (D)

NATALIE AILENE MORENO, BA

*Author affiliations can be found in the back matter of this article

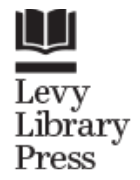

Press

\section{ABSTRACT}

First-generation, low-income (FGLI) medical students are the first in their family to obtain a four-year college degree and to pursue medical education. Unfortunately, these students lack the social capital, financial resources and knowledge of the hidden curriculum of medical school possessed by their non-FGLI peers. Additionally, the intersectionality of SES, race, and gender, with FGLI status contributes to poorer wellbeing, lower self-care, and lower perceptions of support. FGLI students often come from more interdependent, working-class cultural backgrounds than their independent minded peers, which creates a cultural mismatch with the traditional medical school structure. In 2017, the AAMC began to assess first-in-family status within the medical school admissions application, an important consideration for a holistic, diversityoriented approach to shape the medical student body. It is crucial that each medical school continue to build infrastructure which helps FGLI students flourish during the medical school journey.

Underrepresented students also face differences in the type and quality of mentorship they receive, which translates to differences in student preparedness to pursue competitive specialties. The inequalities that FGLI students face have been exacerbated by fewer face-to-face interactions and clinical opportunities in the setting of a more virtual learning environment. Student-led efforts at the University of Michigan Medical School are dedicated to providing FGLI students with community and multiple mentorship opportunities early in medical school. In addition to facilitating near-peer mentorship opportunities with other FGLI students and residents, we have connected students with specialty-oriented mentorship programs, such as Anastomosis (general surgery), Uroversity (urology), and Michigan Ophthalmology Pipeline. These intentional efforts promote FGLI student mentorship from multiple entities, which allows them to
CORRESPONDING AUTHOR:

\section{Jennifer A. Fokas, BA}

University of Michigan Medical School, US

jafokas@med.umich.edu

\section{KEYWORDS:}

medical education; mentorship; first-generation low income; underrepresented students; professional development; pipeline

TO CITE THIS ARTICLE: Fokas JA, Rodoni BM, LaMonica LC, Moreno NA. Traversing the American Dream in Medical School - The FGLI Experience. ISMMS Journal of Science and Medicine. 2021; 1(1): 8, pp. 1-2. DOI: https://doi. org/10.29024/ijsm.38 
find fit in the mentorship relationship, meet mentors in different stages of their careers, and leverage the benefits of the multi-mentor model. We recommend dedicated support and recognition of the FGLI community from medical school leadership. We further suggest building infrastructure for clear pathways to mentorship opportunities as a more equitable approach to medical education that will build greater diversity across all medical specialties.

\section{COMPETING INTERESTS}

The authors have no competing interests to declare.

\section{AUTHOR AFFILIATION}

Jennifer A. Fokas, BA (D) orcid.org/0000-0003-0315-1878

University of Michigan Medical School, US

\section{Bridger M. Rodoni, BS}

University of Michigan Medical School, US

Lauren C. LaMonica, BS, MPH (iD) orcid.org/0000-0003-3625-4566

University of Michigan Medical School, US

\section{Natalie Ailene Moreno, BA}

University of Michigan Medical School, US

(c) 2021 The Author(s). This is an open-access article distributed under the terms of the Creative Commons Attribution 4.0 International License (CC-BY 4.0), which permits unrestricted use, distribution, and reproduction in any medium, provided the original author and source are credited. See http://creativecommons.org/ licenses/by/4.0/.

ISMMS Journal of Science and Medicine is a peer-reviewed open access journal published by Levy Library Press. 